$\underline{\text { Research Articles }}$

\title{
Healthcare seeking behavior for pain in back and extremities in rural population: a community-based estimation of treatment seeking, types and choice of care giver during a period of twelve months in rural Gadchiroli, India
}

\author{
Anand A Bang ${ }^{1}$, Shekhar Y Bhojraj ${ }^{2}$, Mahesh Deshmukh1, Vinay R Joshi ${ }^{3}$, Tushar Yarmal ${ }^{4}$, Sameer Kalkotwar², Abhay T \\ Bang ${ }^{1}$ \\ 1 Society for Education, Action and Research in Community Health (SEARCH), Gadchiroli, Maharashtra, India, ${ }^{2}$ Spine Foundation, Mumbai, \\ Maharashtra, India, ${ }^{3}$ Hinduja Hospital and Research Center, Mumbai, Maharashtra, India, ${ }^{4}$ Naraindas Morbai Budhrani Trust, Mumbai, Maharashtra, \\ India
}

Keywords: rural india, musculoskeletal pain, back pain, healthcare seeking behavior

https://doi.org/10.29392/001c.30747

Journal of Global Health Reports

Vol. 5, 2021

\begin{abstract}
Background
Population based studies to understand the current healthcare seeking behavior of the population for pain in back and extremities are lacking from rural India. We studied: (i) healthcare seeking behavior for pain in back and extremities, (ii) types of care providers sought by the community, and the (iii) factors associated with treatment seeking.
\end{abstract}

\section{Methods}

Two villages were randomly selected from a cluster of 39 villages in the Gadchiroli district of India. Using predetermined criteria, all resident adults $\geqslant 20$ years, were surveyed in January 2010 by the trained community health workers (CHW) by making household visits. Using a structured, pretested questionnaire, they inquired and recorded the history of pain in back and extremities and health care seeking for the same during the previous 12 months.

\begin{abstract}
Results
Out of 2535 eligible adults in two villages, 2259 (89\%) were interviewed. A significant proportion of the participants with back pain and pain in the extremities sought treatment (86.99\%). The maximum number of individuals sought care from private providers (64.64\%) followed by home remedies (61.64\%), government facilities (17.03\%), community health workers (CHW) of Society for Education, Action and Research in Community Health (SEARCH) (12.87\%), Bengali doctors (5.7\%) and traditional healers (6.56\%). Almost equal number of participants with any back pain (88.88\%) and any extremity pain $(88.95 \%)$ sought treatment. The care seeking was significantly more for female participants (odds ratio, $\mathrm{OR}=1.83$, 95\% confidence interval, $\mathrm{CI}=1.32-2.5$ ), in case of severe pain $(\mathrm{OR}=2.0,95 \% \mathrm{CI}=1.29-3.12)$ and in the age group 51 to 60 years $(\mathrm{OR}=2.04$, 95\% CI=1.14-3.67).
\end{abstract}

\section{Conclusions}

A significant number of the individuals with back pain and pain in the extremities in rural Gadchiroli seek care, mainly from private practitioners and resort to application of home remedies whereas the care seeking from the public health facilities is considerably less. Hence there is need to provide care for pain in back and extremities in the public healthcare system.

Back pain (BP) and musculoskeletal pain (MSP) are the commonest form of chronic pain, causing disability and health care expenditure globally. ${ }^{1-4}$ In India, the disorder of joints / pain were the second and fourth most common causes of outpatient clinic visits and out of pocket expenses among all non-communicable diseases, respectively. ${ }^{5}$
Heavy physical work is a known risk factor for BP and MSP6 and hence agrarian rural communities across the world are at a high risk of BP and MSP. 7,8 The rural population of India is 833.1 million, which is $68.84 \%$ of the total population of India. ${ }^{9}$ This rural population is constrained with overall lack of health care providers, including for BP and 
MSP. While the ratio of physicians per 1000 population in India is only $0.857,10$ the ratio of urban to rural density for physicians was 3.8 , signifying selective concentration of physicians in the urban areas. ${ }^{11}$ Additionally, according to a recent study, most of the health care providers from the rural areas are in the private sector (86\%). Furthermore, most of the providers from the private sector are 'informal providers', i.e. providers without any formal medical training or degree, accounting for $68 \%$ of the total health care provider population in rural India. ${ }^{12}$

This dearth of trained health care providers, coupled with the fact that despite the significant burden of BP and MSP, it is not a priority under the National Rural Health Mission, the flagship program of the government of India for improving the health care status of the rural communities in India, ${ }^{13}$ results in the reliance of the rural communities for treatment of BP and MSP on other health care sources. Nevertheless, there is a dearth of population-based data from rural India on the health care seeking for BP and MSP which information can help in the development of appropriate public health interventions.

As there is a significant need for provision of affordable, accessible, and acceptable interventions for BP and MSP, understanding the current healthcare seeking behavior of the population is the first step in designing such interventions. We conducted this study with the aims to understand (a) the current healthcare seeking behavior in terms of seeking treatment, (b) existing types of care providers in the community and the (c) factors associated with seeking treatment, home remedies and other treatments.

\section{METHOD}

\section{STUDY SETTING AND SAMPLE SIZE}

This study of health care seeking and choice of care givers was nested in a population based, cross sectional, interview based survey of the prevalence of pain in the back and extremities (PBE) in rural Gadchiroli. The primary outcome for sample size estimation of the main study was period prevalence of low back pain in the adults ( $\geqslant 20$ years of age), based on which a sample of minimum 1800 was calculated. The study setting, population characteristics, study design, sample size calculation and the selection of the villages have been described in detail earlier. ${ }^{14}$

\section{DATA COLLECTION}

The data were collected from 01 January 2010 to 25 January 2010.

\section{QUESTIONNAIRE DEVELOPMENT}

A standardized questionnaire in vernacular language (Marathi) was developed to interview the participants and record the following information; a) episodes of PBE at different body sites, b) intensity, duration and season of the episode, c) whether treatment was sought for the pain, d) whether home remedies were used or treatment from an external health care provider was sought and e) the type of health care provider in the 12 months preceding the survey from January 2009 to January 2010. This questionnaire was pilot tested in villages and in the rural clinic of Society for Education, Action and Research in Community Health (SEARCH) and modified appropriately before using in the survey.

\section{STATISTICAL METHODS}

A database was constructed for data entry using FOX PRO Version 2.0. Descriptive statistics included mean, medians and ranges for continuous variables and proportions for categorical variables were estimated. Categorical data are presented as frequencies and continuous data are presented as mean \pm standard deviation (SD). Multiple logistic regression was performed to evaluate the predictors of treatment seeking for PBE. Analyses were conducted using Stata 10.0 (STATA Corp, College Station, Texas, USA).

\section{ETHICS APPROVAL}

The research followed the tenets of the Declaration of Helsinki. Ethical approval for this nested study was granted as part of the main study, by the Institutional Ethical Committee of SEARCH formed according to the guidelines by the Indian Council for Medical Research. Consent was obtained first at the cluster level in the study villages 15 days before starting the survey. The community leaders (Village Council Leaders and members, school teacher and presidents of microfinance self-help groups) were explained the purpose and scope of the study including the benefits to the villagers (availability of referral care in SEARCH clinic and the care through a village clinic). Informed written consent in vernacular language in a standard format was obtained from individual participants after explaining the nature and benefits of the study. The benefits provided during the study included free consultation by spine surgeons and rheumatologists in a clinic conducted in the same village at a later date. For those who needed further evaluation, laboratory investigations, as well as imaging with Magnetic Resonance Imaging (MRI) and X-ray including transport were provided free of cost. For patients needing pharmacotherapy, and physiotherapy, these services were also provided free of cost and for those needing surgical interventions, such services were provided at significantly subsidized costs. The community health workers (CHW) discussed these benefits using a printed pamphlet.

\section{RESULTS}

\section{THE STUDY POPULATION AND ITS CHARACTERISTICS}

The total population of the two villages was 3735 out of which 2535 (67.9\%) were adults $\geqslant 20$ years of age and were eligible to participate in the study (Figure 1). Of these, 2259 (89\%) were interviewed, 276 (11\%) were either absent from the village (migrated for work) or unable to communicate due to very old age or disability. The response rate was higher in Mudza (92\%) than Bamhani (86\%), and for females (91.3\%) than males $(87.5 \%)$.

The mean age of the participants was 41.7 years (SD 15.6) and $51 \%$ of the study participants were women. The occupation was primarily farming and farm labour (78\%). While about $70 \%$ of the study participants were literate, only $10 \%$ 
of the participants had schooling beyond 10 years. The age, caste, education and occupation distribution of the participants have been presented in detail earlier. ${ }^{14}$

\section{TREATMENT SEEKING FOR PAIN IN BACK AND EXTREMITIES ACCORDING TO SOCIODEMOGRAPHIC CHARACTERS}

Of the 2259 individuals surveyed, 1876 (83\%) had an episode of PBE in the twelve months preceding the survey (Table 1, Table S1 in Online Supplementary Document). Overall, 86.99\% (95\% confidence interval, $\mathrm{CI}=85.38-88.48$ ) of the participants with any pain sought treatment. The treatment seeking was more by females $(90.36 \%$, 95\% $\mathrm{CI}=88.41-92.08)$ than males $(82.73 \%, 95 \% \mathrm{CI}=79.97-85.24)$. Similarly, more married participants sought care $(88.2 \%$, 95\% CI=86.57-89.68) than unmarried (73.72\%, 95\% $\mathrm{CI}=66.07-80.43)$. The treatment seeking was similar for the three categories of castes, namely scheduled caste (SC) / nomadic tribes (NT), scheduled tribes (ST) and all other castes (88.57\%, 87.64\% and $86.69 \%$ respectively). Care was sought the most by illiterate participants $(90.76 \%$, 95\% CI= 88.58-92.63), participants within the age group 51 to 60 years $(92.14 \%, 95 \% \mathrm{CI}=88.34-95.01)$, and those with severe pain $(92.8 \%, 95 \% \mathrm{CI}=89.54-95.28)$.

\section{TYPE OF CARE GIVER SOUGHT FOR PAIN IN BACK AND EXTREMITIES ACCORDING TO SOCIO-DEMOGRAPHIC CHARACTERS}

Of the 1632 participants who sought treatment, the maximum sought care from private providers (64.64\%) followed by home remedies (61.64\%) (Table 2, Figure 2, Table S1 in Online Supplementary Document). The other less frequently used sources of care were government facilities (17.3\%), CHWs of SEARCH (12.87\%), informal providers (5.7\%) and traditional healers (6.56\%). Across all the sociodemographic categories the care seeking was highest from private doctors and application of home remedies. Amongst the different categories, the CHWs were sought the most for severe pain (19.88\%) followed by illiterate participants (17.2\%). Bengali doctors were sought the most by females (8.03\%), SC / NT participants (8.39\%), illiterates $(8.2 \%)$ as well as those educated more than $12^{\text {th }}$ standard (9.09\%), by participant with age more than 50 years (20.13\%) and by participants with severe pain (14.29\%). Across all the categories, the maximum care seeking from government hospitals was by the ST participants (29.52\%). Traditional healers were sought most by participants with age more than 60 years (11.6\%) and those with severe pain (13.66\%).

\section{PROPORTION OF PARTICIPANTS SEEKING TREATMENT AND HOME REMEDIES ACCORDING TO ANATOMICAL SITE}

Overall $86.85 \%$ of the participants with any pain sought treatment (Table 3). Almost equal number of participants with any back pain (88.88\%), any extremity pain (88.95\%), thoracic pain (92.04\%), neck pain (91.88\%) and pain in the superior extremity (91.37) sought treatment. Overall, of the

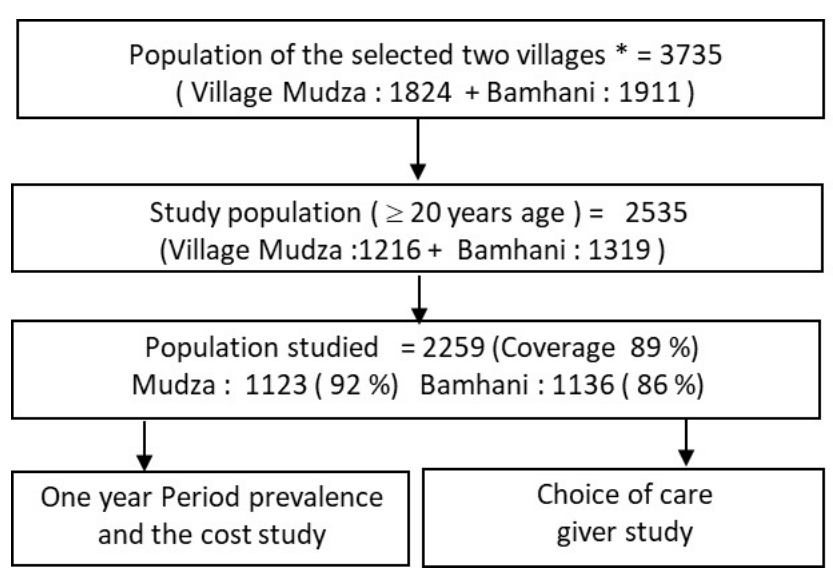

Figure 1. Study design flowchart

* 2010 population register

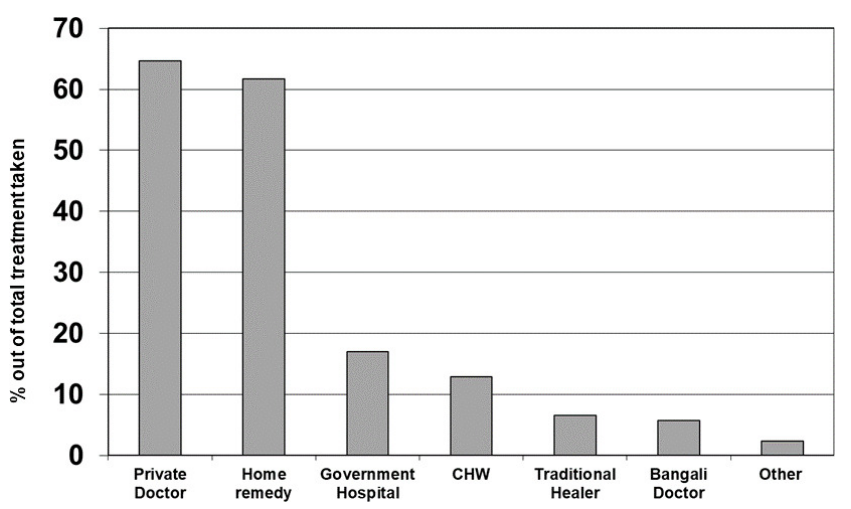

Figure 2. Type of care giver sought for pain in back and extremities

1632 participants who sought treatment, the maximum were with any back pain (93.5\%) whereas the least were with thoracic pain (49.57\%).

\section{PROPORTION OF PARTICIPANTS SEEKING TREATMENT FROM DIFFERENT CARE PROVIDERS ACCORDING TO ANATOMICAL SITE OF PAIN}

The distribution of the participants according to pain at different anatomical sites seeking different care giver generally mirrors that according to different sociodemographic categories. Maximum care seeking was from private doctors followed by application of home remedies. There was no significant difference in care seeking from different care providers according to different anatomical sites of pain (Table 4).

\section{PREDICTORS OF TREATMENT SEEKING FOR PAIN IN BACK AND EXTREMITIES}

In a multivariate analysis, the care seeking was significantly more for female participants than males (odds ratio, $\mathrm{OR}=1.83$, 95\% $\mathrm{CI}=1.32-2.5)$, in participants with severe pain compared to mild pain ( $\mathrm{OR}=2.0,95 \% \mathrm{CI}=1.29-3.12)$ and in the participants within the age group 51 to 60 years com- 
Table 1. Treatment seeking for pain in back and extremities according to sociodemographic characters over 12-months in rural Gadchiroli (January 2009 to December 2009)

\begin{tabular}{|c|c|c|c|c|c|}
\hline \multirow[t]{2}{*}{ Characteristics } & \multirow[t]{2}{*}{ Total } & \multirow[t]{2}{*}{ Any pain present } & \multicolumn{3}{|c|}{ Treatment Taken for PBE* } \\
\hline & & & No & $\%$ of any pain present & $95 \% \mathrm{Cl}^{\dagger}$ \\
\hline Participants & 2259 & 1876 & 1632 & 86.99 & $(85.38,88.48)$ \\
\hline \multicolumn{6}{|l|}{ Sex: } \\
\hline Males & 1101 & 828 & 685 & 82.73 & $(79.97,85.24)$ \\
\hline Females & 1158 & 1048 & 947 & 90.36 & $(88.41,92.08)$ \\
\hline \multicolumn{6}{|l|}{ Marital Status: } \\
\hline Unmarried & 283 & 156 & 115 & 73.72 & $(66.07,80.43)$ \\
\hline Married & 1976 & 1720 & 1517 & 88.20 & $(86.57,89.68)$ \\
\hline \multicolumn{6}{|l|}{ Caste: } \\
\hline $\mathrm{SC} \neq / \mathrm{NT}^{\S}$ & 215 & 175 & 155 & 88.57 & $(82.9,92.87)$ \\
\hline $\mathrm{ST} T^{l l}$ & 318 & 259 & 227 & 87.64 & $(83.01,91.39)$ \\
\hline Others & 1726 & 1442 & 1250 & 86.69 & $(84.82,88.39)$ \\
\hline \multicolumn{6}{|l|}{ Education: } \\
\hline Illiterate & 887 & 833 & 756 & 90.76 & $(88.58,92.63)$ \\
\hline $1-4$ years & 395 & 349 & 308 & 88.25 & $(84.4,91.43)$ \\
\hline $5-7$ years & 274 & 221 & 189 & 85.52 & $(80.17,89.88)$ \\
\hline $8-10$ years & 472 & 325 & 261 & 80.31 & $(75.56,84.49)$ \\
\hline 11 - 12 years & 190 & 125 & 96 & 76.80 & $(68.41,83.87)$ \\
\hline$>12$ years & 41 & 23 & 22 & 95.65 & $(78.05,99.88)$ \\
\hline \multicolumn{6}{|l|}{ Age: } \\
\hline 20 - 30 years & 678 & 471 & 378 & 80.25 & $(76.36,83.75)$ \\
\hline 31 - 40 years & 516 & 427 & 370 & 86.65 & $(83.05,89.73)$ \\
\hline 41 - 50 years & 471 & 418 & 376 & 89.95 & $(86.66,92.66)$ \\
\hline 51 - 60 years & 301 & 280 & 258 & 92.14 & $(88.34,95.01)$ \\
\hline$>60$ years & 293 & 280 & 250 & 89.29 & $(85.05,92.65)$ \\
\hline \multicolumn{6}{|l|}{ Severity of Pain: } \\
\hline Mild & 1529 & 1529 & 1310 & 85.68 & $(83.81,87.39)$ \\
\hline Severe & 347 & 347 & 322 & 92.80 & $(89.54,95.28)$ \\
\hline
\end{tabular}

* Pain in the Back and Extremities

$\dagger$ Confidence Interval

$\ddagger$ Scheduled Caste

$\S$ Nomadic Tribes

|| Scheduled Tribe

pared to 20 to 30 years $(\mathrm{OR}=2.04,95 \%$ CI $1.14-3.67)$. There was no significant difference in the probability of care seeking in case of married and unmarried participants, across different castes and educational categories. The care seeking was similar across different age groups except in case of the age group 51 to 60 years which was significant more than the age group 20 to 30 years (OR=2.04, 95\% $\mathrm{CI}=1.14-3.67)$. This was in tune with the observation that the participants within the age group 51 to 60 years sought maximum care $(92.14 \%)$ whereas the participants within the age group 20 to 30 sought the least care (80.25\%).

\section{DISCUSSION}

Overall, a high proportion of the participants with pain in back and extremities sought treatment (86.99\%). The care seeking was high for all the sociodemographic categories as well as for pains at different anatomical sites. The care seeking was significantly more for female participants, in case of severe pain and in the age group 51 to 60 years. Of the 1632 participants who sought treatment, the maximum sought care from private providers (64.64\%) followed by home remedies (61.64\%). The proportion of participants seeking care from government facilities, community health workers of SEARCH, informal provider's doctors and traditional healers were significantly less. Almost equal number of participants with any back pain (88.88\%) and any extremity pain $(88.95 \%)$ sought treatment. For different anatomical sites of pain also the maximum care seeking was from private doctors followed by application of home remedies.

To the best of our knowledge, this is the one of the earliest study from rural India reporting the care seeking pat- 
Table 2. Type of care giver sought for pain in back and extremities according to sociodemographic characters over 12-months in rural Gadchiroli (January 2009 to December 2009)

\begin{tabular}{|c|c|c|c|c|c|c|c|}
\hline \multirow[t]{2}{*}{ Characteristics } & \multicolumn{7}{|c|}{$\%$ of treatment taken from different care providers $(n=1632)$} \\
\hline & $\mathrm{CHW}$ & $\begin{array}{l}\text { Private } \\
\text { Doctor }\end{array}$ & $\begin{array}{l}\text { Bengali } \\
\text { Doctor }\end{array}$ & $\begin{array}{c}\text { Government } \\
\text { Hospital }\end{array}$ & $\begin{array}{l}\text { Home } \\
\text { remedy }\end{array}$ & $\begin{array}{c}\text { Traditional } \\
\text { Healer }\end{array}$ & Other \\
\hline Participants & 12.87 & 64.64 & 5.70 & 17.03 & 61.64 & 6.56 & 2.33 \\
\hline \multicolumn{8}{|l|}{ Sex: } \\
\hline Males & 8.91 & 60.29 & 2.48 & 17.23 & 61.90 & 3.07 & 3.07 \\
\hline Females & 15.73 & 67.79 & 8.03 & 16.90 & 61.46 & 9.08 & 1.80 \\
\hline \multicolumn{8}{|l|}{ Marital Status: } \\
\hline Unmarried & 6.96 & 50.43 & 1.74 & 14.78 & 65.22 & 1.74 & 2.61 \\
\hline Married & 13.32 & 65.72 & 6.00 & 17.21 & 61.37 & 6.92 & 2.31 \\
\hline \multicolumn{8}{|l|}{ Caste: } \\
\hline $\mathrm{SC}^{*} / \mathrm{NT}^{\dagger}$ & 14.19 & 54.84 & 8.39 & 19.35 & 64.52 & 5.16 & 1.29 \\
\hline $\mathrm{ST} T^{\ddagger}$ & 2.20 & 62.11 & 5.73 & 29.52 & 56.83 & 8.37 & 3.96 \\
\hline Others & 14.64 & 66.32 & 5.36 & 14.48 & 62.16 & 6.40 & 2.16 \\
\hline \multicolumn{8}{|l|}{ Education: } \\
\hline Illiterate & 17.20 & 72.35 & 8.20 & 16.40 & 61.90 & 9.26 & 1.06 \\
\hline 1 - 4 years & 9.74 & 63.31 & 2.92 & 20.45 & 59.09 & 4.87 & 2.92 \\
\hline $5-7$ years & 6.35 & 62.96 & 1.59 & 16.40 & 65.08 & 3.17 & 3.70 \\
\hline 8 - 10 years & 11.11 & 52.11 & 5.36 & 15.33 & 60.92 & 4.98 & 3.45 \\
\hline 11 - 12 years & 8.33 & 48.96 & 3.13 & 16.67 & 60.42 & 2.08 & 4.17 \\
\hline > 12 years & 4.55 & 50.00 & 9.09 & 18.18 & 72.73 & 4.55 & 4.55 \\
\hline \multicolumn{8}{|l|}{ Age: } \\
\hline 20 - 30 years & 8.73 & 50.00 & 3.17 & 12.96 & 68.52 & 3.17 & 2.12 \\
\hline 31 - 40 years & 12.16 & 62.97 & 4.05 & 17.03 & 64.59 & 4.86 & 4.05 \\
\hline 41 - 50 years & 13.30 & 64.10 & 3.99 & 21.01 & 57.71 & 8.24 & 2.66 \\
\hline 51 - 60 years & 15.50 & 74.03 & 8.53 & 20.54 & 55.81 & 6.59 & 0.78 \\
\hline$>60$ years & 16.80 & 80.40 & 11.60 & 13.60 & 58.80 & 11.60 & 1.20 \\
\hline \multicolumn{8}{|l|}{ Severity of Pain: } \\
\hline Mild & 11.15 & 62.82 & 3.59 & 17.18 & 63.36 & 4.81 & 2.14 \\
\hline Severe & 19.88 & 72.05 & 14.29 & 16.46 & 54.66 & 13.66 & 3.11 \\
\hline
\end{tabular}

* Scheduled Caste

$\dagger$ Nomadic Tribes

$\ddagger$ Scheduled Tribes

tern for pain in the back and extremities, care seeking for pain at different anatomical sites and the factors affecting care seeking, in a community which is largely agrarian and involved in manual labour. We do not know if there are regional differences in the care seeking behaviour and care providers for pain in back and extremities. Nevertheless the findings of this study may be considered applicable to most of the rural agrarian Indian population considering the similar overall socioeconomic work profile and provision of care. At the same time we suggest that more population-based studies should be conducted in different parts of rural India, possibly employing larger sample sizes, to identify any regional differences in the care seeking and care provision for pain in back and extremities.

This study reveals several important characteristics of the healthcare seeking behavior for PBE in rural India. As a majority of the participants (86.99\%) with PBE sought treat- ment, it underlines the burden of the condition and critical need to have qualified healthcare providers for this problem. Though there is no comparative population based data from rural India, in another study from urban Indonesia, $73 \%$ of all the participants had sought treatment for their MSP. ${ }^{15}$ The pattern of outpatient care provision for PBE mainly by private practitioners is similar to the overall pattern of outpatient medical care provision predominantly by the private sector in India. ${ }^{16}$ This may be due to the wide availability of injectable medicines and intravenous fluids with the private providers, both formal and informal which are perceived as highly effective modes of treatment of back and joint pain. ${ }^{17}$

Although heavily subsidized care is available from government healthcare facilities, only $17 \%$ of the participants seeking care sought care from these facilities. This may be a reflection of the fact that this problem is not considered 
Table 3. Proportion of participants taking treatment and home remedies of the total participants with pain in back and extremities according to anatomical site of pain in rural Gadchiroli over 12 months (January 2009 to December 2009)

\begin{tabular}{|c|c|c|c|c|}
\hline \multirow[t]{2}{*}{ Variables } & \multirow[t]{2}{*}{ Total } & \multicolumn{3}{|c|}{ Treatment taken $(n=1632)$} \\
\hline & & $\begin{array}{l}\text { Treatment } \\
\text { taken }\end{array}$ & $\begin{array}{l}\% \text { of those with pain at that } \\
\text { site }\end{array}$ & $\begin{array}{c}\% \text { of those who sought } \\
\text { treatment }\end{array}$ \\
\hline Any back pain & 1717 & 1526 & 88.88 & 93.50 \\
\hline Neck & 985 & 905 & 91.88 & 55.45 \\
\hline Thoracic & 879 & 809 & 92.04 & 49.57 \\
\hline Low back & 1585 & 1414 & 89.21 & 86.64 \\
\hline Any extremities pain & 1602 & 1425 & 88.95 & 87.32 \\
\hline Superior Extremity ${ }^{*}$ & 1124 & 1027 & 91.37 & 62.93 \\
\hline Inferior Extremity ${ }^{\dagger}$ & 1417 & 1281 & 90.40 & 78.49 \\
\hline $\begin{array}{l}\text { Any pain (Back/ } \\
\text { Extremity) }\end{array}$ & 1879 & 1632 & 86.85 & 100.00 \\
\hline
\end{tabular}

* (Any one of Shoulder, Arm, Elbow, Forearm, Wrist, Hand + Fingers, Trapezius / Scapula)

$\dagger$ (Any one of Hip/Buttocks, Groin, Thigh, Knee, Leg / calf, Ankle, Heel, Foot + digits)

a public health priority currently in India. This could partly be due to the lack of population-based data on the burden of PBE, its non-fatal nature as well as a possible assumption that care for the problem is easily available and simple. This could also be due to the underdeveloped public health care system in rural Gadchiroli, as in contrast, in another study from Tamilnadu, a state with relatively better developed public health care system, $55.7 \%$ of those taking medication had sought care from public health facilities, while only $35.2 \%$ had sought care from private healthcare facilities. ${ }^{18}$

The less proportion of participants (12.87\%) seeking care from community health workers of SEARCH trained in providing aspirin for pain management can be explained by both the belief of the community in the need of injections for pain relief, mismatch between the expectation of the patient for pain relief and the actual relief provided by Aspirin and the perception of Aspirin being considered as a routine medication ineffective for pain relief. It also underlines the need to train and strengthen the CHW and expand their toolkit including rational simple therapeutic measures for pain relief.

The small proportion of participants (6.56\%) seeking pain relief from traditional healers may be indicating the changing perceptions of the rural community with increasing education and awareness regarding medical care including more reliance on allopathic medical care. This seems to be corroborated with the finding that the participants with age more than 60 years (11.6\%) sought the maximum care from traditional healers, indicative of the prevalent perception about the role of traditional healers in the older population than the younger and more educated one. Those with severe pain (13.66\%) may have sought care more from traditional healers due to lack of satisfaction from allopathic and other remedies and / or may have use of multiple therapies at the same time with the hope of earliest pain relief. The minimal proportion of participants seeking pain relief from informal providers (5.7\%) was though surprising considering that the informal providers also use injections readily, and hence this needs to be explored further.

That $61.64 \%$ of the participants seeking pain relief resorted to home remedies is significant and underline the crucial role of various simple home remedies including massage, application of oils, liniments and ointments easily available. This was significantly more compared to another study from rural Tamilnadu where $28.5 \%$ of the people seeking care were applying home remedies. ${ }^{18}$ Though we could not identify whether the use of home remedies preceded that of seeking care from external providers, this possibility cannot be ruled out including the parallel use of home remedies. In fact the use of home remedies being second only to care seeking from private doctors and far more than any other source of care identifies the existing faith of the communities in simple home remedies, and provides an opportunity to educate regarding more such remedies which can be easily self-used by the communities limiting the dependence on external care providers.

There was hardly any difference between various anatomical sites regarding care seeking. Whereas overall $86.85 \%$ of the participants with any pain sought treatment, there was hardly any difference between participants with any back pain (88.88\%) and any extremity pain (88.95\%) seeking care. In fact considering the nature of pain in back and extremities affecting multiple sites, ${ }^{19}$ it would be artificial to distinguish between pain at different sites as the reason of seeking care. More often than not, probably the participants sought for pain overall, than for only a particular site.

The only factors significantly affecting care seeking were gender and the intensity of pain. Females sought care more than males (OR 1.83) and participants with severe pain sought care more than mild (OR 2.0). The intensity of the pain as a factor affecting care seeking is self-explanatory; nevertheless what is interesting is the significantly more care seeking (and higher prevalence of pain in back and extremities) by females. This precludes any gender bias against women limiting their ability of care seeking; instead if it is there it probably works in favor of females. This 
Table 4. Proportion of participants seeking treatment from different care providers according to anatomical site of pain over 12 months (January 2009 to December 2009)

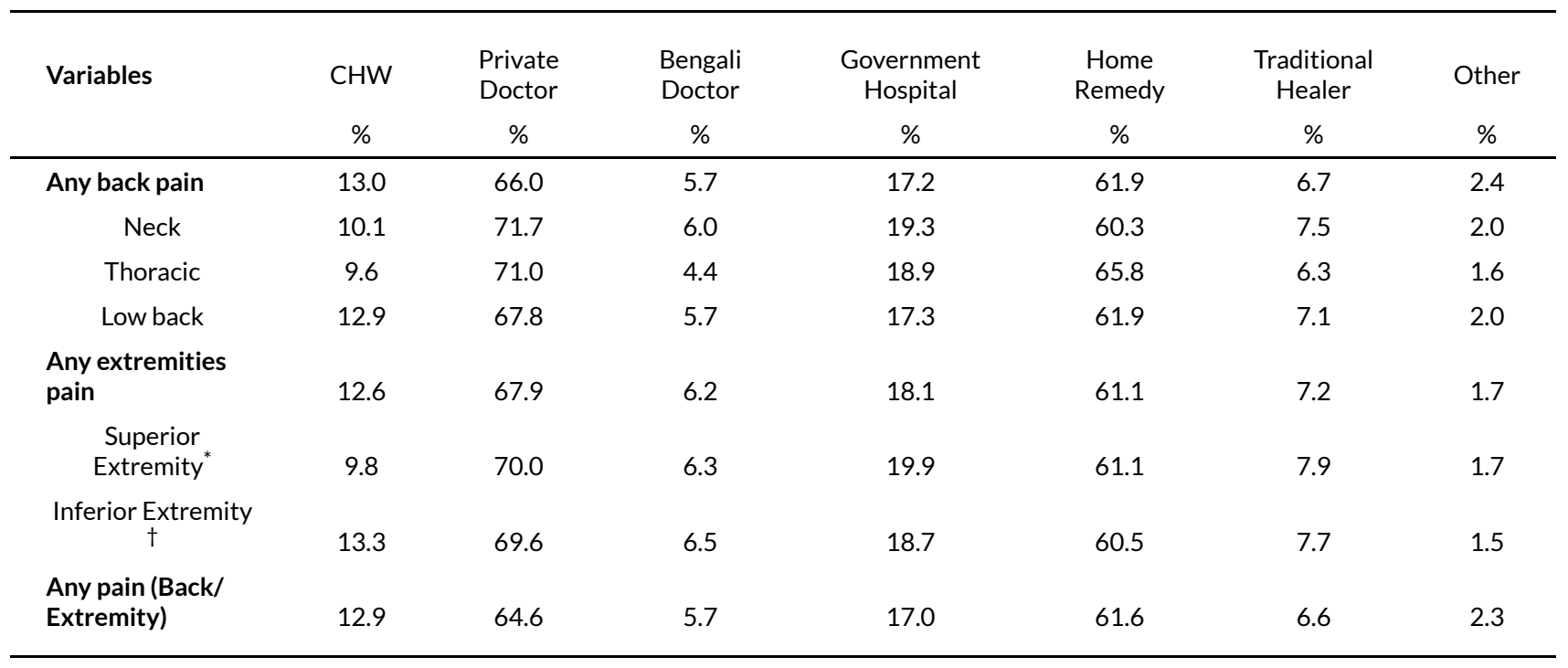

* (Any one of Shoulder, Arm, Elbow, Forearm, Wrist, Hand + Fingers, Trapezius / Scapula)

$\dagger$ (Any one of Hip/Buttocks, Groin, Thigh, Knee, Leg / calf, Ankle, Heel, Foot + digits)

is a significant finding, as in contrast, in a study from Bangladesh, the care seeking by women was pronouncedly less despite the suffering. ${ }^{20}$ The fact that caste (a crucial social variable in rural India) and education did not affect care seeking is interesting and merits further exploration.

Finally, in different age groups the care seeking was generally similar except in the case of the age group 51 to 60 years in which it was significantly more than the age group 20 to 30 years (OR 2.04). Age as a factor associated with health care seeking behaviour was also observed in another study from South East Asia. ${ }^{15}$ In absolute terms also the care seeking was maximum in participants within the age group 51 to 60 years (92.14\%) and least in participants within the age group 20 to 30 (80.25\%). This can be explained to some extent by higher pain tolerance, probably lesser disability and movement limitations due to pain in the younger age groups as well as significantly more prevalence of pain in the age group 51 to 60 years (93\%) compared to 20 to 30 years (6\%).

Why is there significant care seeking? Partly it is due to the chronic and episodic nature of the problem with the mean duration of any pain in a year of 166 days the higher prevalence of chronic pain of $55 \%,{ }^{19}$ and the ensuring activity limitation ${ }^{2,21,22}$ leading to frequent visits to different care providers. The dissatisfaction appears to be due to a mismatch between the expectations of complete relief from pain from the treatment and the outcome. At the same time, the current low utilization of the community health workers in providing pain relief presents as an opportunity to explore more effective and simple therapies which can be entrusted with the CHWs, reducing reliance of patients on private providers as well as economic burden associated with it as observed in other studies. ${ }^{23-25}$ The National Rural Health Mission engaging approximately 8.5 Lakh Accredited Social Health Activists (ASHAs) as community health workers provide an opportunity to do so by training in dispensing analgesic tablets under appropriate supervision using treatment algorithms and by increasing awareness about this problem among communities.

The study had several strengths, which lend confidence to the estimates obtained. Some of the strengths were in the design of the nested study including measures of rigorous quality control implemented as the use of data quality checks and linking of the remuneration of the $\mathrm{CHW}$ with the data quality as described earlier. ${ }^{14}$ The information bias was also limited as the data collection was done by CHWs with more than 15 years of experience using a well-tested, structured and robust questionnaire. Additionally this study reports the direct experience of the participants and their choices rather than only perceived choices.

The limitation was the sampling method used in the study, whereby instead of randomly selecting subjects over several villages, we chose all the subjects in two villages. This may have limited possible contextual diversity in the study. This was due to the fact that this particular study was part of the nested study. Additionally, the sample size was not calculated with care seeking behavior as the primary outcome.

\section{CONCLUSIONS}

In conclusion, this population-based study in rural Gadchiroli demonstrates significant care seeking for pain in back and extremities in the rural societies involved in hard manual work, especially farming. Due to the absence of effective care provision from public health facilities, and possibly due to a mismatch between the expectations of the patients and care available in the public health system, majority of the care provision is by the private doctors. Systematic epidemiological studies need to be conducted to understand the nature of care seeking and care provision for this problem in other part of rural India. Considering that pain in back and extremities is a major public health priority in rural communities, the public health system should 
Table 5. Association between seeking treatment with sociodemographic characteristics in rural Gadchiroli for pain in back and extremities over 12 months (January 2009 to December 2009)

\begin{tabular}{|c|c|c|}
\hline \multirow[t]{2}{*}{ Variables } & \multicolumn{2}{|c|}{ Dependent variable - Treatment taken } \\
\hline & Odds Ratio & $95 \% \mathrm{Cl}^{*}$ \\
\hline \multicolumn{3}{|l|}{ Sex } \\
\hline Males & 1 & \\
\hline Females & 1.84 & $(1.35,2.50)$ \\
\hline \multicolumn{3}{|l|}{ Marital status } \\
\hline Unmarried & 1 & \\
\hline Married & 1.30 & $(0.28,2.11)$ \\
\hline \multicolumn{3}{|l|}{ Caste } \\
\hline Other castes & 1 & \\
\hline $\mathrm{SC}^{\dagger} / \mathrm{NT}^{\ddagger}$ & 1.03 & $(0.62,1.70)$ \\
\hline $\mathrm{ST} \S$ & 1.02 & $(0.68,1.55)$ \\
\hline \multicolumn{3}{|l|}{ Education } \\
\hline Illiterate & 1 & \\
\hline $1-4$ years & 1.01 & $(0.66,1.55)$ \\
\hline $5-7$ years & 0.90 & $(0.55,1.46)$ \\
\hline $8-10$ years & 0.68 & $(0.44,1.06)$ \\
\hline $11-12$ years & 0.64 & $(0.36,1.13)$ \\
\hline$>12$ years & 4.23 & $(0.54,32.94)$ \\
\hline \multicolumn{3}{|l|}{ Age groups } \\
\hline 20 - 30 years & 1 & \\
\hline 31 - 40 years & 1.22 & $(0.80,1.86)$ \\
\hline $41-50$ years & 1.55 & $(0.95,2.51)$ \\
\hline $51-60$ years & 2.05 & $(1.14,3.67)$ \\
\hline$>60$ years & 1.44 & $(0.82,2.50)$ \\
\hline \multicolumn{3}{|l|}{ Intensity of pain } \\
\hline Mild & 1 & \\
\hline Severe & 2.01 & $(1.29,3.12)$ \\
\hline $\begin{array}{l}\text { * Confidence Interval } \\
\text { † Scheduled Caste } \\
\text { † Nomadic Tribes } \\
\text { § Scheduled Tribe }\end{array}$ & & \\
\hline
\end{tabular}

identify the current bottlenecks leading to sub optimal utilization of pain alleviation measures by the communities and undertake appropriate measures to develop interventions which are culturally appropriate, incorporate expectations of patients including behaviour change and are developed according to the principles of rational therapy.

\section{ACKNOWLEDGEMENTS}

We thank the people, community health workers, volunteers and leaders of the village Mudza and Bamhani who participated in the study and made all the arrangements. We thank Dr. Rani Bang, SEARCH, Gadchiroli for her support in conceiving and conducting the study. We thank Dr Yogesh Kalkonde for reviewing the manuscript.

\section{FUNDING}

The study was funded by Sir Dorabji Tata Trust, the Spine Foundation, Mumbai, and SEARCH, Gadchiroli, India.

\section{AUTHORSHIP CONTRIBUTIONS}

Conceived and designed the study: AAB, ATB, SYB, VRJ, MD, SK. Conducted the study: AAB, MD, TY, ATB. Analyzed the data: MD, AAB, ATB. Contributed materials / analysis tools: ATB, SYB, SK, VRJ. Wrote the draft manuscript: AAB. Reviewed the manuscript: ATB.

\section{COMPETING INTERESTS}

The authors completed the Unified Competing Interest form at http://www.icmje.org/disclosure-of-interest/ (available upon request from the corresponding author) and declare no conflicts of interest. 


\section{CORRESPONDENCE TO:}

Dr. Abhay Bang, MD, M.P.H.

Director, SEARCH, Shodhgram, PO Gadchiroli, Maharash- tra, India 422605.

search.gad@gmail.com

Submitted: March 30, 2021 GMT, Accepted: April 06, 2021 GMT 


\section{REFERENCES}

1. Campbell C, Muncer SJ. The causes of low back pain: A network analysis. Soc Sci Med. 2005;60(2):409-419. doi:10.1016/i.socscimed.2004.0 $\underline{5.013}$

2. Ehrlich GE. Low back pain. Bull World Health Organ. 2003;81(9):671-676. http://www.pubmedcentral.nih.g ov/articlerender.fcgi?artid=PMC2572532

3. Murray CJ, Vos T, Lozano R, Naghavi M, Flaxman $\mathrm{AD}$, Michaud C, et al. Disability-adjusted life years (DALYs) for 291 diseases and injuries in 21 regions, 1990-2010: a systematic analysis for the Global Burden of Disease Study 2010. Lancet. 2012;380(9859):2197-2223. http://linkinghub.elsevie r.com/retrieve/pii/S0140673612616894

4. Woolf AD. The Bone and Joint Decade 2000-2010. Ann Rheum Dis. 2000;59(2):81-82. doi:10.1136/ard.5 $\underline{9.2 .81}$

5. Mahal A, ME AK. The Economic Implications of NonCommunicable Disease for India. The World Bank; 2010. http://siteresources.worldbank.org/HEALTHNU TRITIONANDPOPULATION/Resources/281627-10956 98140167/EconomicImplicationsofNCDforIndia.pdfAv ailable

6. Barrero LH, Hsu YH, Terwedow H, et al. Prevalence and Physical Determinants of Low Back Pain in a Rural Chinese Population. Spine (Phila Pa 1976). 2006;31(23):2728-2734. doi:10.1097/01.brs.00002445 83.35982.ea

7. Haq SA, Darmawan J, Islam MN, Uddin MZ, Das BB, Rahman F, et al. Prevalence of rheumatic diseases and associated outcomes in rural and urban communities in Bangladesh: a COPCORD study. $J$ Rheumatol. 32(2):348-353. http://www.ncbi.nlm.nih.g ov/pubmed/15693098

8. Louw QA, Morris LD, Grimmer-Somers K. The prevalence of low back pain in Africa: a systematic review. BMC Musculoskelet Disord. 2007;8(1):105. do $\mathrm{i}: 10.1186 / 1471-2474-8-105$

9. Chandramouli C, General R. Census of India 2011. Provisional Population Totals. Government of India; 2011. https://censusindia.gov.in/2011-prov-results/pa per2/data files/india/paper2 1.pdf

10. World Bank. Physicians (per 1,000 People) - India. $\underline{\mathrm{h}}$ ttps://data.worldbank.org/indicator/SH.MED.PHYS.Z S?locations =IN
11. Sudhir A, Victoria F. The Health Work Force in India: Human Resources for Health Observer. https://w ww.who.int/hrh/resources/16058health_workforce_In dia.pdf

12. Das J, Daniels B, Ashok M, Shim EY, Muralidharan $\mathrm{K}$. Two Indias: The structure of primary health care markets in rural Indian villages with implications for policy. Social Science \& Medicine. Published online June 15, 2020:112799. doi:10.1016/j.socscimed.2020.1 $\underline{12799}$

13. Government of India Ministry of Health and Family Welfare. National Rural Health Mission (2005-2012) Mission Document. Published online 2005. https://www.nhm.gov.in/images/pdf/guideline s/nrhm-guidelines/mission document.pdf

14. Bang AA, Bhojraj SY, Deshmukh M, et al. Burden of pain in back and extremities in rural population: a community-based estimation of 12-month period prevalence, distribution and duration of pain in rural Gadchiroli, India. J Glob Health. 2021;11. doi:10.7189/ jogh.11.12001

15. Andarini S, Arif AZ, Al Rasyid H, Wahono CS, Kalim H, Handono K. Factors associated with health care seeking behavior for musculoskeletal pain in Indonesia: A cross - sectional study. Int J Rheum Dis. 2019;22(7):1297-1304. doi:10.1111/1756-185x.13536

16. International Institute for Population Sciences. National Family Health Survey (NFHS-3), 2005-06: India. International Institute for Population Sciences; 2007. http://rchiips.org/nfhs/NFHS-3

17. Deshmukh SA, Kalkonde YV, Deshmukh MD, Bang AA, Bang AT. Healthcare seeking behavior for back and joint pain in rural gadchiroli, India: a populationbased cross-sectional study. Indian J Community Med. 2014;39(4):229-234. doi:10.4103/0970-0218.143026

18. Kirubakaran S, Dongre AR. Chronic musculoskeletal pain among elderly in rural Tamil Nadu: Mixed-method study. J Family Med Prim Care. 2019;8(1):77. doi:10.4103/ifmpc.jfmpc_290_17

19. Bang AA, Bang AT, Bhojraj SY, Deshmukh M, Yarmal T, Kalkotwar S, et al. Economic Burden of Pain in Back and Extremities in the adult population: A community based estimates in rural Gadchiroli, India. J Glob Health.

20. Nawrin S, Hasan M. Musculoskeletal Pain among Rural Homemakers and their Health Seeking Behaviors. Curr Tr \& Med Sci. 2020;2(1):2020. doi:1 0.33552/ctcms.2020.02.000527 
21. Bang AA, Bang AT, Bhojraj SY, Deshmukh M, Yarmal T, Kalkotwar S, et al. Disability due to pain in back and extremities in rural population: A community-based study in Gadchiroli, India. J Glob Health. Published online 2021.

22. Manchikanti L. Epidemiology of low back pain. Pain Phys. 2000;3(2):167-192. doi:10.36076/ppj.2000/ $\underline{3 / 167}$

23. Bang AT, Bang RA, Reddy HM. Home-Based Neonatal Care: Summary and Applications of the Field Trial in Rural Gadchiroli, India (1993 to 2003). J Perinatol. 2005;25(S1):S108-S122. doi:10.1038/sj.jp.7 $\underline{211278}$
24. Browne G, Roberts J, Gafni A, et al. Economic evaluations of community-based care: lessons from twelve studies in Ontario. J Eval Clin Pract. 1999;5(4):367-385. doi:10.1046/j.1365-2753.1999.001 91.x

25. Okello D, Floyd K, Adatu F, Odeke R, Gargioni G. Cost and cost-effectiveness of community-based care for tuberculosis patients in rural Uganda. Int J Tuberc Lung Dis Off J Int Union Against Tuberc Lung Dis. 2003;7(9 Suppl 1):S72-S79. 


\section{SUPPLEMENTARY MATERIALS}

\section{Online Supplementary Document}

Download: https://www.joghr.org/article/30747-healthcare-seeking-behavior-for-pain-in-back-and-extremities-inrural-population-a-community-based-estimation-of-treatment-seeking-types-and-choice/attachment/77504.docx 